\title{
Literasi fungsional bermuatan anti Kekerasan Berbasis Gender (KBG) di Kampung Bogor Kabupaten Manokwari Papua Barat
}

Yolanda Holle*, Els Tieneke Rieke Katmo, \& Josina Waromi

Universitas Papua

*yolandaholle@yahoo.co.id

\begin{abstract}
Integrate gender base violence awareness into functional literacy learning program is aimed to develop modul about functional literacy contained gender base violence, conduct field study and applied modul of function literacy for Papuan women and men. This program is targeted community in Bogor sub district that consist og two neigboorhood groups, Bogor and Irmajaya. Most of the participant are farmers who lack of education. They commonly originated from Arfak and Biak. Learning method that used in this program is group-based approach, stakeholders' incorporation in the program, role plays and colored picture and participatory approach. The result that will achieved from this program are integrated gender base violence in functional literacy modul that cultural appropriate. Four agents of change as pioner gender base violence awareness.
\end{abstract}

\begin{abstract}
Abstrak Pembelajaran literasi bermuatan anti kekerasan berbasis gender (KBG) dilakukan dengan tujuan mengembangkan modul literasi fungsional bermuatan anti kekerasan yang sesuai dengan kebutuhan sosial budaya masyarakat Papua, dan melaksanakan proses belajar mengajar menggunakan modul literasi fungsional bagi kelompok mama dan bapak Papua. Sasaran pembelajaran literasi ditujukan bagi masyarakat di Kampung Bogor yang terbagi atas Dusun Bogor dan Dusun Irman Jaya. Peserta didik memiliki latar belakang pendidikan rendah, bermata pencaharian sebagai petani, dan sebagian besar berasal dari suku Hatam dan Biak. Metode pembelajaran yang digunakan adalah pembelajaran kelompok, pembelajaran melalui pendekatan tokoh gereja dan kepala suku, pembelajaran lewat gambar berwarna dan permainan, serta pembelajaran partisipatif peserta. Hasil yang diperoleh tersedia modul literasi fungsional bermuatan anti kekerasan yang sesuai dengan kebutuhan sosial budaya masyarakat Papua. Proses belajar dapat menghasilkan 2 orang bapak dan 2 orang mama sebagai agen penggerak masyarakat yang dapat menggerakkan dan mendifusikan materi literasi KBG kepada masyarakat.
\end{abstract}

Keywords: gender base violence awareness; functional literacy; Papua

\section{¿ OPEN ACCESS}

Citation: Holle, Y., E. T. R. Katmo, \& J. Waromi. 2019. Literasi fungsional bermuatan anti kekerasan berbasis gender (KBG) di Kampung Bogor Kabupaten Manokwari Papua Barat. Riau Journal of Empowerment 2(2): 55-59 https://doi.org/10.31258/raje.2.2.55-59

Paper type: Community service

Received: 2019-07-30 Revised: 2019-09-11 Accepted: 2019-09-13

Language: Bahasa Indonesia (id)

Funding: Winrock Usaid

ISSN 2623-1549 (online), 2654-4520 (print)

C 2019 Yolanda Holle. The article by Author is licensed under a Creative Commons Attribution 4.0 International License. This license permits unrestricted use, distribution, and reproduction in any medium, provided the original author and source are credited. 


\section{PENDAHULUAN}

Papua Barat sebagai salah satu wilayah dengan kondisi masyarakat buta aksara cukup besar yaitu 32.000 lebih penduduk yang tidak bisa membaca dan menulis (Badan Pusat Statistik Kabupaten Manokwari, 2015). Diprediksi angka tersebut akan bertambah pada masyarakat di wilayah kampung yang jauh dari pusat perkotaan yang belum banyak memiliki fasilitas pendidikan dan tenaga pendidik. Khususnya di Kabupaten Manokwari, Badan Pusat Statistik Kabupaten Manokwari (2015) menunjukkan bahwa jumlah penduduk yang tidak pernah ke sekolah sebesar $23,92 \%$ dan secara terpilah gender $2,71 \%$ diantaranya adalah perempuan. Jika dilihat berdasarkan umur, maka perempuan dengan usia 7-24 tahun sebanyak 3,58\% tidak pernah menikmati bangku pendidikan sedangkan laki-laki hanya sekitar 0,98 \% (Badan Pusat Statistik Kabupaten Manokwari, 2015).

Dampak ketidakmampuan membaca dan menulis yang tinggi mengakibatkan tingkat pemahaman, kepekaan dan pengetahuan terhadap sesuatu fenomena menjadi rendah (Herlina et al., 2018), misalnya tindak kekerasan berbasis gender lama kelamaan menjadi hal yang biasa meskipun dalam kehidupan sehari-hari baik kaum perempuan maupun kaum laki-laki mengalaminya. P2TP2A Kabupaten Manokwari (Badan Pemberdayaan Perempuan dan Anak Kabupaten Manokwari, 2014) memberikan informasi bahwa, korban kekerasan dalam rumah tangga adalah ibu dengan usia lebih dari 24 tahun dan tingkat pendidikan korban rata-rata tergolong tinggi yaitu SMA dan PT. Hal ini menandakan bahwa korban berani melapor ke P2TP2A karena korban memahami dan peka terhadap kekerasan yang dialaminya. Berbeda dengan korban yang berpendidikan rendah tidak ditemui. Pada situasi tersebut nampak bahwa korban kekerasan yang berpendidikan rendah, belum atau tidak memahami dan peka terhadap kekerasan yang dialaminya. Dalam jangka panjang selain mengalami kekerasan tindak kekerasan, perempuan tidak mampu untuk berkontribusi penuh dalam pembangunan.

Kegiatan literasi fungsional bagi masyarakat Papua yang berada jauh dari pusat kota belum banyak dijangkau oleh pemerintah melalui program pendidikan buta aksara termasuk pada wilayah sasaran Kampung Bogor. Selain itu, program pendidikan buta aksara hanya bermuatan pengenalan abjan tanpa memasukkan muatan kekerasan berbasis gender. Tujuan kegiatan pengabdian ini adalah (1) mengembangkan modul literasi fungsional bermuatan anti kekerasan yang sesuai dengan kebutuhan sosial budaya masyarakat Papua, (2) melaksanakan proses belajar mengajar menggunakan modul literasi fungsional bermuatan anti kekerasan bagi kelompok mama dan bapak Papua.

Kampung Bogor terletak di distrik Prafi berjarak tempuh kurang lebih $80 \mathrm{~km}$ yang ditempuh dengan kendaraan roda empat selama dua jam lebih dari pusat ibukota Manokwari. Letak kampung yang terpisah dan terpencil dari kampung-kampung lainnya mengakibatkan sulitnya masyarakat berkomunikasi dengan orang lain di luar komunitas dan terhambatnya arus informasi. Rata-rata pendidikan perempuan yang sudah berkeluarga berada pada tingkat SD dan sebagian besar putus sekolah. Fenomena pendidikan rendah menyebabkan pemahaman masyarakat akan tindak kekerasan terhadap perempuan kurang dipahami. Kekerasan dipahami sebagai hal biasa dan wajar dialami dalam kehidupan perempuan, sehingga banyak perempuan yang tidak melaporkan kejadian kekerasan tersebut. Tindakan kekerasan terhadap perempuan yang banyak dialami masyarakat adalah kekerasan fisik dan verbal.

\section{METODE PENERAPAN}

Lokasi pengabdian dilakukan Kampung Bogor yang terbagi atas Dusun Bogor dan Dusun Irman Jaya. Sasaran pembelajaran literasi ditujukan bagi kelompok mama dan kelompok bapak, dengan waktu pelaksanaan selama 10 bulan terhitung dari bulan Februari hingga November 2018.

Metode pembelajaran yang digunakan adalah (1) pembelajaran kelompok, (2) pembelajaran melalui pendekatan tokoh gereja dan kepala suku, (3) pembelajaran lewat 
gambar berwarna dan permainan, serta (4) pembelajaran partisipatif peserta (Azwanti et al., 2019).

\section{HASIL DAN KETERCAPAIAN SASARAN}

Pembelajaran literasi bermuatan anti kekerasan berbasis gender (KBG) berfokus pada dua hal yaitu (1) mengembangkan modul literasi fungsional bermuatan anti kekerasan yang sesuai dengan kebutuhan sosial budaya masyarakat Papua, dan (2) melaksanakan proses belajar mengajar menggunakan modul literasi fungsional bagi kelompok mama dan bapak Papua.

\section{Modul Literasi Bermuatan Anti Kekerasan Berbasis Gender}

Pengembangan modul literasi disusun oleh Tim Unipa dengan merunjuk pada modul diskusi komunitas untuk kelas ayah dan ibu yang dihasilkan oleh Widarsih et al. (2014) dan Saeroni dan Thontowi (2014). Modul terpakai selanjutnya direvisi sesuai dengan keadaan dan kebutuhan bapa dan mama di kampung Bogor dengan menampilkan narasi Melanesia seharihari Papua dan gambar Papua. Proses penyusunan modul dilakukan dalam beberapa tahap yaitu tinjauan situasi dan kebutuhan sasaran, penyusunan materi dengan fokus utama gambargambar, penerapan modul melalui proses pembelajaran, dan revisi modul setelah proses pembelajaran. Modul pembelajaran terdiri dari 12 modul muatan kekerasan berbasis gender.
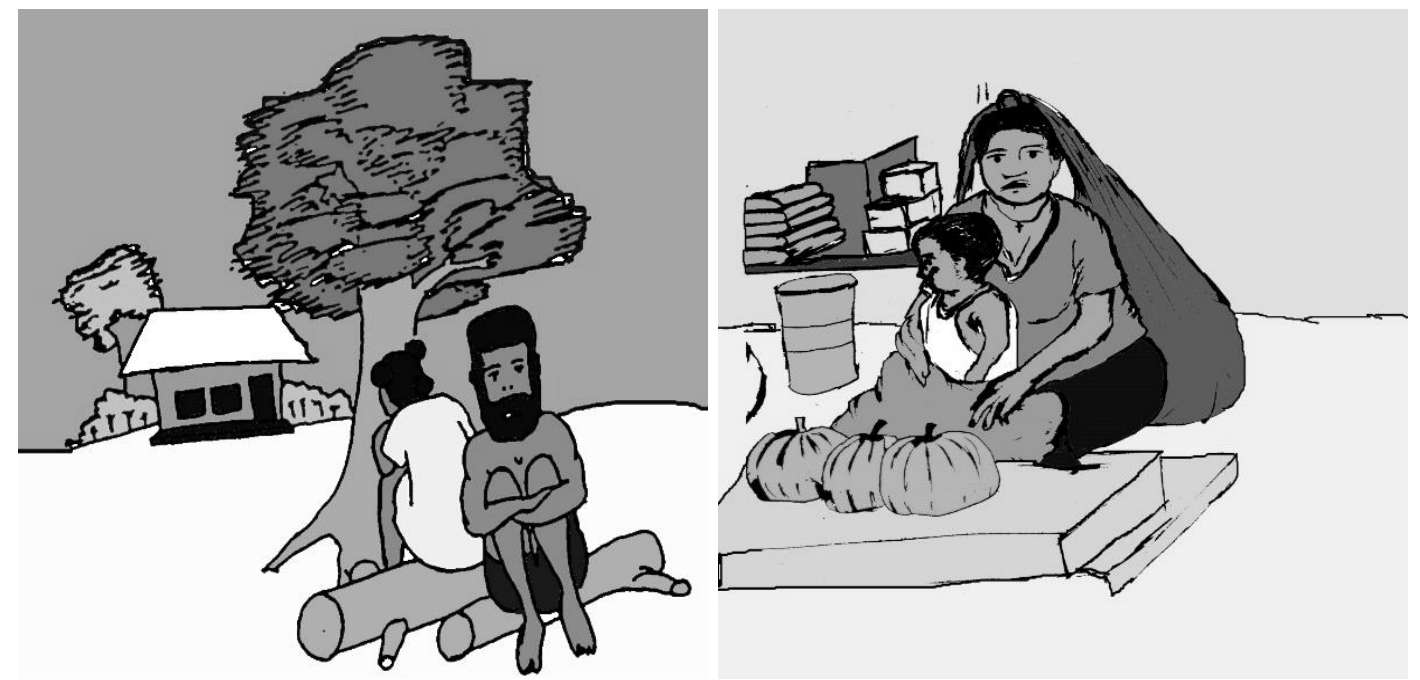

Gambar 1. Contoh Gambar Modul Literasi

TOPIK: PEREMPUAN YANG DIHARAPKAN

Tong paling harap bapak-bapak dong jadi:

1. Rajin kerja rumah tangga

2. Rajin jaga anak

3. Rajin kasih bersih rumah

4. Tidak cerewet

5. Juga bisa cari kerja

6. Bisa bantu mama bela dan angkat kayu bakar

Gambar 2. Contoh Narasi Modul Literasi

Modul literasi bermuatan gender yang disusun atas kondisi dan kebutuhan masyarakat Papua dengan menggunakan narasi Melanesia sehari-hari Papua dan gambar-gambar berwarna 
masyarakat Papua, telah menciptakan komunikasi yang efektif bagi pengajar dengan masyarakat Papua. Disisi pihak, menciptakan ketertarikan masyarakat dan suasana belajar yang tidak membosankan.

Kesulitan penyusunan modul terletak pada pembuatan gambar-gambar yang mencirikan masyarakat Papua. Kondisi ini terjadi karena kurangnya sumberdaya manusia di Papua dalam bidang desain gambar.

\section{Proses Belajar Mengajar Menggunakan Modul Literasi Bermuatan Anti Kekerasan Berbasis Gender}

Proses belajar mengajar literasi melibatkan 35 orang bapak dan 67 orang mama di Kampung Bogor. Pengetahuan baru yang diterima masyarakat tentang kekerasan berbasis gender (KBG) terdiri dari muatan sex dan gender, perempuan laki-laki dan budaya patriakhi, gender dan permainan, komunikasi, berbagi peran, relasi sehat tanpa kekerasan, menjadi mama dan bapa dalam pengasuhan, pengasuhan anak, kesehatan reproduksi, kesehatan ibu, dan mengelola ekonomi keluarga. Sedangkan literasi yang dipahami antara lain abjad A (anak), B (bapak, bagi), M (mama, mainan), S (susu, sayang), K (kekerasan, komunikasi), U (pukul).

Materi kekerasan berbasis gender cukup banyak diminati oleh kelompok mama dengan alasan (1) membantu keluarga hidup damai, (2) mengetahui organ-organ reproduksi yang sehat, (3) menjaga dan memelihara anak dengan baik, (4) membina hubungan komunikasi yang harmonis dengan suami, dan (5) mengeahui beberapa abjad. Sebaliknya, minat pada kelompok bapak sedikit dengan alasan (1) materi kekerasan berbasis gender hanya cocok bagi mama-mama, dan (2) tugas dan tanggung jawab laki-laki dan perempuan sudah diatur sejak dahulu kala dan tidak dapat dirubah.
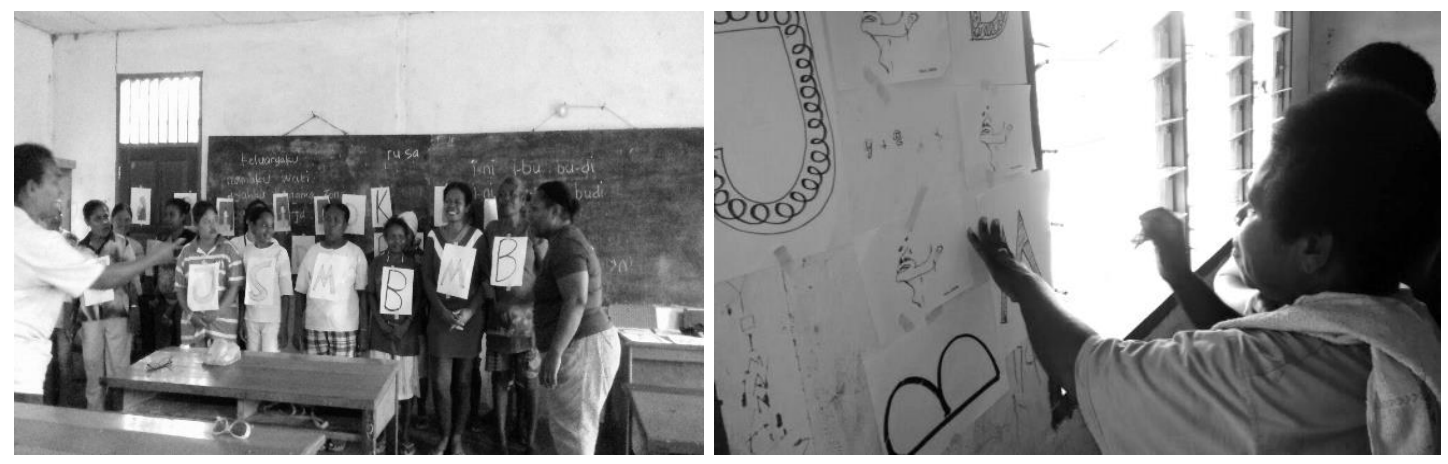

Gambar 3. Proses Belajar Mengajar Literasi Muatan KBG

Kesulitan dalam pelaksanaan proses belajar muatan KBG yang ditemui antara lain (1) tidak terbiasanya mama dan bapak untuk berkumpul dalam kelompok, (2) tidak terbiasanya mamamama dalam mengemukakan pendapat,(3) Sulitnya menggumpulkan mama dan bapak dalam suatu waktu tertentu, dan (4) terganggunya proses belajar mama dikarenakan harus memperhatikan anak yang dibawanya pada saat belajar. Menyikapi permasalahan dilakukan beberapa strategi yang dilakukan antara lain (1) mendatangi dan mengajak mama dan bapak dari rumah ke rumah, (2) melakukan kegiatan tepat pada hari minggu setelah mama dan bapak selesai melaksanakan ibadah, (3) membentuk kelas anak-anak dengan memberikan materi permainan dan pujian, (4) mengkaitkan materi KBG dengan firman Tuhan agar dapat mudah dipahami, dan (5) Berusaha mencari figur bapak-bapak yang bisa memotivasi kelompok bapak untuk terlibat.

\section{KESIMPULAN}

Hasil yang diperoleh antara lain (1) tersedia modul literasi fungsional bermuatan anti kekerasan yang sesuai dengan kebutuhan sosial budaya masyarakat Papua, (2) proses belajar dapat menghasilkan 2 orang bapak dan 2 orang mama sebagai agen penggerak masyarakat 
yang dapat menggerakkan dan mendifusikan materi literasi KBG kepada masyarakat. Dampak setelah selesai kegiatan pengabdian yaitu masyarakat sendiri mengusulkan program KBG ke dalam program pembangunan kampung.

Rekomendasi kelanjutan pengabdian selanjutnya antara lain (1) mendifusikan penggunaan modul bagi fasilitator pemerintah, LSM, maupun Perguruan tinggi dalam pembinaan masyarakat Papua, (2) melakukan pembinaan literasi fungsional bermuatan KBG bagi masyarakat Papua di kampung Wasegi Pop, (3) melanjutkan pembinaan KBG dengan fokus pembinaan ekonomi rumah tangga di dusun Irman Jaya.

\section{UCAPAN TERIMA KASIH}

Ucapan terima kasih disampaikan kepada Winrock Usaid melalui program Usaid Bersama yang telah menyediakan dana pada kegiatan literasi kekerasan berbasis gender.

\section{Daftar Pustaka}

1. Azwanti, N., A. Fajrin, \& Y. Mardiansyah. 2019. Pelatihan penggunaan aplikasi Paint dan pembuatan blog untuk meningkatkan kreatifitas pendidik pada HIMPAUDI Batam Center. Riau Journal of Empowerment 2(1): 9-13. https://doi.org/10.31258/raje.2.1.14

2. Badan Pemberdayaan Perempuan dan Anak Kabupaten Manokwari. 2014. Laporan Tahunan Pemberdayaan Perempuan dan Anak. Manokwari: Badan Pemberdayaan Perempuan dan Anak Kabupaten Manokwari.

3. Badan Pusat Statistik Kabupaten Manokwari. 2015. Manokwari dalam Angka. Manokwari: Badan Pusat Statistik Kabupaten Manokwari.

4. Herlina, S., W. Winarti, \& C. Wahyudi. 2018. Meningkatkan pengetahuan dan kemampuan kader kesehatan melalui pelatihan bantuan hidup dasar. Riau Journal of Empowerment 1(2): 8590. https://doi.org/10.31258/raje.1.2.11

5. Saeroni, \& M. Thontowi. 2014. Modul diskusi komunitas untuk kelas ayah (Program Laki-Laki Peduli). Yogyakarta: Rifka Annisa Women's Crisis Centre.

6. Widarsih, R. E., N. Kodriati, \& F. I. Harjanti. 2014. Modul Diskusi Komunitas Untuk Kelas Ibu. Yogyakarta: Rifka Annisa Women's Crisis Centre. 